\title{
PENETAPAN KAWASAN BERSEJARAH SEBAGAI SEBUAH USAHA PELESTARIAN
}

\author{
Ari Widyati Purwantiasning \\ Jurusan Arsitektur Universitas Muhammadiyah Jakarta \\ arwityas@yahoo.com
}

\author{
Diterima: 29-08-2021 Direview : 01-09-2021 Direvisi : 02-09-2021 Disetujui: 09-09-2021
}

ABSTRAK. Sebuah Kawasan bersejarah yang memiliki nilai sejarah dan berkarakter akan menjadi lebih signifikan jika telah ditetapkan sebagai sebuah Kawasan bersejarah secara hukum baik dengan ketetapan tingkat lokal, nasional maupun internasional. Tulisan ini bertujuan untuk mengkaji lebih dalam mengenai apa itu penetapan Kawasan bersejarah dan bagaimana manfaatnya bagi masyarakat khususnya dan negara umumnya. Metode yang digunakan dalam kajian ini adalah metode eksploratif dengan pembahasan menggunakan pendekatan deskriptif naratif. Narasi hasil yang dipaparkan dalam artikel ini adalah bagaimana manfaat penetapan Kawasan bersejarah menjadi signifikan ketika dikaitkan dengan identitas sebuah bangsa umumnya dan sebuah kota khususnya.

Kata Kunci: Kawasan bersejarah, pelestarian, penetapan, identitas

ABSTRACT. A historic area with historical value and character will be more significant if legally designated as a historical area with local, national, or international regulations. This paper aims to examine more deeply what the designation of a historical site is and how it benefits the community in particular and the country in general. The method used in this study is an explorative method with a discussion using a descriptive narrative approach. The final result presented in this article is how the benefits of establishing a historic area become significant when associated with the identity of a nation in general and a city in particular.

Keywords: historical site, preservation, designation, identity

\section{PENDAHULUAN}

Beberapa waktu yang lalu dunia dikejutkan oleh beberapa berita utama yang beredar secara daring baik berita lokal maupun berita kelas dunia seperti BBC maupun CNN. Berita utama di bulan Juni 2021 (Gambar 1) menyebutkan mengenai ancaman UNESCO terhadap pemerintah lokal kota Liverpool yang tentunya juga terkait pemerintah pusat Negara Inggris. Ancaman UNESCO adalah peringatan akan ancaman pencabutan Status World Heritage atau Pusaka Dunia terhadap Kota Liverpool. UNESCO menganggap karakter Kota Liverpool yang signifikan berangsurangsur hilang karena adanya pembangunan yang cukup merusak citra dan karakter Kota Liverpool sebagai sebuah Pusaka Dunia (BBC News, 2021).

Satu bulan sejak diberitakannya ancaman dari UNESCO di bulan Juni 2021 tersebut, muncul baru yang lebih mengejutkan yaitu dicabutnya secara resmi status World Heritage bagi Kota Liverpool (Gambar 2). Hal ini tidak hanya mengejutkan masyarakat Inggris, namun juga masyarakat dan pemerhati pelestarian di seluruh dunia. Hal ini mungkin saja terjadi dengan World Heritage lainnya di dunia yang saat ini juga mengalami penurunan kualitas yang semakin diperkuat karena kondisi pandemic covid-19 sehingga pengelolaan dan pemeliharaannya menjadi tidak optimal.

\section{Unesco report says Liverpool should lose World Heritage status}

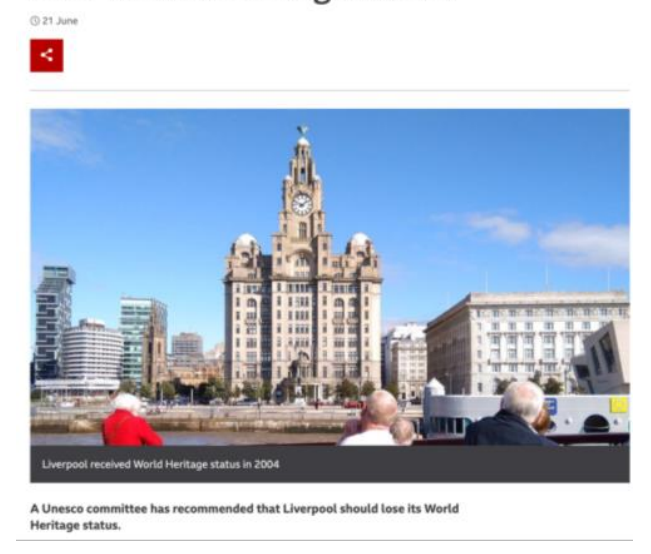

Gambar 1. Berita di bulan Juni 2021 tentang ancaman UNESCO terhadap kota Liverpool (Sumber: BBC News, diakses 28 Agustus 2021)

Building Design online pada tanggal 21 Juli 2021 memberitakan tentang pencabutan status World Heritage Kota Liverpool (Hopkirk, 2021). Tepat satu bulan setelah diberitakan BBC News tentang ancaman UNESCO terhadap Kota Liverpool. Ada kalimat dari pernyataan UNESCO yaitu "with deep regret', "significant loss to its authenticity and integrity" dan kata 
"irreversible" di dalam pemberitaannya. Hal ini memperkuat betapa seriusnya kondisi Kota Liverpool sehingga perlu adanya pencabutan status World Heritage atas kota tersebut. UNESCO menganggap adanya kecerobohan proses pada pemerintah baik lokal Liverpool maupun pusat Inggris dalam melaksanakan berbagai pembangunan sehingga aturanaturan dan kaidah-kaidah konservasi serta kewajiban untuk memelihara Kawasan bersejarah tersebut tidak dipenuhi dengan baik.

\section{n Unesco strips world heritage status from Liverpool}

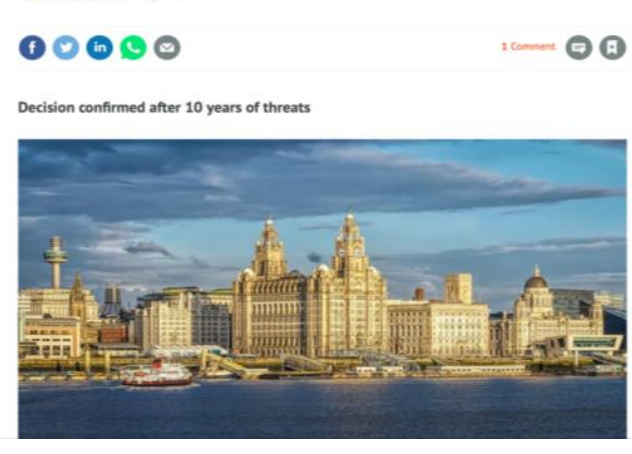

Gambar 2. Berita di bulan Juli 2021 tentang pencabutan status World Heritage terhadap Kota Liverpool

(Sumber: Building Design OnInie, diakses 28 Agustus 2021)

Negara Inggris merupakan satu dari sekian banyak negara di dunia yang sangat peduli dengan masalah pelestarian bangunan bersejarah. Banyak kota-kota di Inggris yang menjadi proyek percontohan dalam kegiatan pelestarian bangunan dan Kawasan bersejarah. Sejak peran penunjukkan daerah atau Kawasan konservasi serta manajemen konservasi diserahkan dari pemerintah pusat Inggris ke pemerintah lokal pada setiap kotanya, definisi atas apa yang disebut sebagai daerah yang secara khusus disebut atau ditetapkan sebagai Kawasan bersejarah dan arsitektur bersejarah dicerminkan dari karakter lokal masing-masing. Selanjutnya banyak peneliti berusaha untuk menjabarkan definisi dari area konservasi sebagai area yang berbeda yang memiliki karakteristik bersejarah, seperti yang disampaikan oleh Worskett (1969). 'a conservation area is the area of a significant historical and social relationship compared to the rest of the town, which must be seen in the context of the whole town both for historic and visual reasons and in order to provide a proper context in which to plan for conservation.'

Worskett, 1969, p.46

Area ini tidak dimaksudkan hanya sematamata untuk dipertahankan saja namun juga untuk dikonservasikan dan kemungkinan akan mendapatkan pengembangan sedikit di dalamnya.

Sangat disayangkan bahwa beberapa tahun terakhir, terlihat perubahan- perubahan yang cepat - banyak bangunan tua yang dimusnahkan secara dashyat dan banyak bangunan baru dibangun yang dirasa tidak sesuai dengan lingkungan sekitarnya serta kebutuhan dari masyarakat lokal, seperti keberadaan bangunan-bangunan tua sebelumnya. Dalam merespon kondisi ini, pemerintah lokal dan masyarakat merasa perlu diterapkannya konsep konservasi dalam menyelamatkan kota bersejarah mereka. Sementara itu, sebagai pengaruh pergerakan modernisasi dimana masyarakatnya menyanjung keberadaan teknologi, mereka tetap saja mengingat dan menyadari bahwa kenyataannya budaya dan sejarah tetap menjadi hal yang kuat untuk dipertahankan (Brolin, 1976).

Conservation will be concerned not only with historic buildings or areas which contain historic buildings but also with their setting and its character,...... standing by itself, a building has no meaning other than which comes from the intrinsic quality of its architecture'

\section{Worskett, 1969}

Berita lain yang mengejutkan masyarakat di dunia muncul satu minggu setelah pemberitaan dicabutnya Kota Liverpool sebagai World Heritage, adalah diberitakannya ancaman UNESCO terhadap dua buah World Heritage di Istanbul, Turki. Dua World Heritage tersebut diberitakan dalam BIANET akan dicabut statusnya sebagai World Heritage dalam waktu dekat (Bianet Online, 2021). 


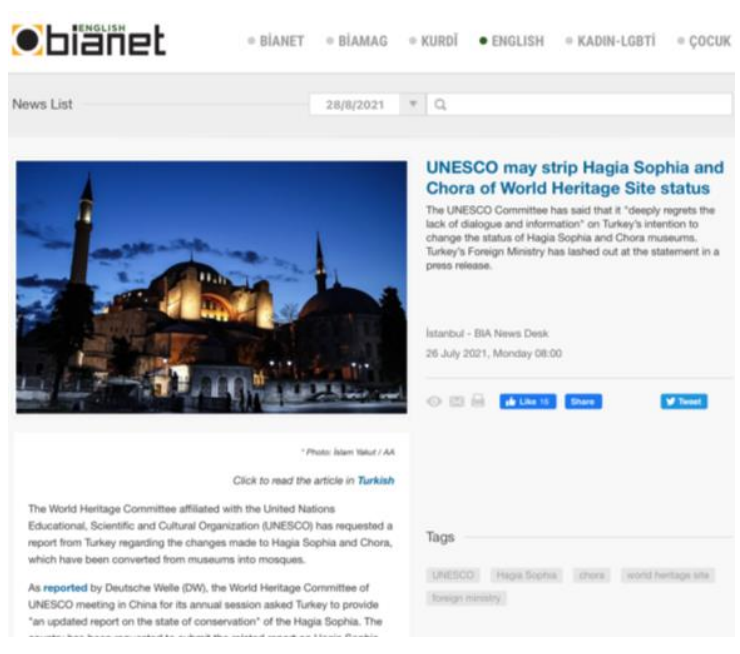

Gambar 3. Berita di bulan Juli 2021 tentang ancaman UNESCO terhadap Hagia Sophia dan Chora Museum, Istanbul, Turki

(Sumber: BIANET, diakses 28 Agustus 2021)

Hagia Sophia yang berusia ratusan tahun merupakan bangunan bersejarah yang tidak hanya memiliki nilai sejarah dan berkarakter secara arsitektural, namun juga memiliki nilai spiritual bagi masyarakat Turki. Bangunan yang beralih fungsi berkali-kali sebagai gereja, masjid, museum dan masjid lagi ini juga memiliki nilai budaya yang tinggi yang mewakili gaya arsitektur Bizantium pada masanya.

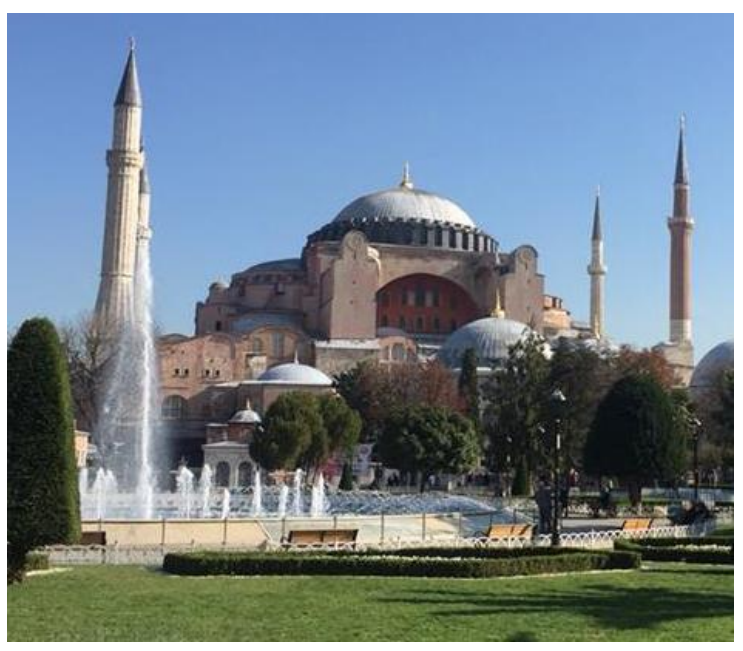

Gambar 4. Bangunan Bersejarah Hagia Sophia, Istanbul, Turki

(Sumber: Dokumentasi Peneliti, 2017)

Hagia Sophia dan Museum CHora merupakan komponen bagian dari Kawasan Bersejarah yang berstatus World Heritage di Istanbul, Turki. Mirip dengan Hagia Sophia, Chora Museum juga merupakan bangunan bersejarah yang beralih fungsi berkali-kali dari mulai Gereja bergaya Bizantium kemudian menjadi Masjid Utsmaniyah dan saat ini menjadi Museum Chora.

Sejak dua berita yang sangat mengejutkan tersebut, Indonesia yang memiliki banyak bangunan bersejarah dan dua belas diantaranya memiliki status World Heritage tentunya sangat prihatibn dengan kondisi tersebut. Terlebih dengan adanya status terancamnya beberapa Pusaka Dunia Indonesia yang akan dicabut dari statusnya dari World Heritage yaitu Candi Borobudur, Taman Nasional Komodo dan Hutan Hujan Tropis Sumatera. Ancaman dari UNESCO sangat beralasan didasari dengan adanya beberapa pembangunan di sekitar Kawasan bersejarah yang dilindungi tersebut. Dengan adanya ancaman dari UNESCO ini, BPPI atau Badan Pelestarian Pusaka Indonesia beberapa waktu yang lalu menyelenggarakan beberapa audiensi dengan pemerintah pusat baik PUPR. BEKRAF, SEKRETARIAT NEGARA dan juga KEMENTRIAN PENDIDIKAN DAN KEBUDAYAAN REPUBLIK INDONESIA. Hal ini bertujuan untuk mengatur strategi dalam menanggapi UNESCO (BPPI Online, 2021).

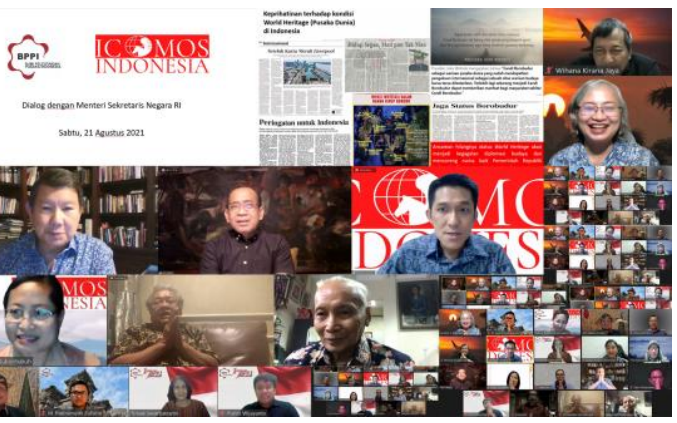

Gambar 5. Kegiatan audiensi dengan beberapa bidang terkait yang diselenggarakan oleh BPPI di bulan Agustus 2021

(Sumber: BPPI online, diakses 28 Agustus 2021)

\section{METODE PENELITIAN}

Seperti yang telah disampaikan di atas, bahwa dalam penelitian ini metode penelitian yang digunakan adalah dengan metode kualitatif di mana dalam analisis dan ulasannya dilakukan dengan naratif deskriptif. Dalam mengumpulkan data-data terkait dengan penetapan Kawasan bersejarah dilakukan secara daring, sehingga beberapa sumber merupakan sumber sekunder yang juga dilengkapi dan diperkuat dengan beberapa sumber primer. Sumber primer digunakan untuk membandingan satu data dengan lainnya untuk dianalisis dengan didukung 
sumber sekunder seperti literatur dan teori yang berkaitan.

\section{PEMBAHASAN}

Dalam tulisan ini, Saya mengangkat beberapa contoh status penetapan Kawasan bersejarah di Indonesia yang dapat dianalisis dan diulas sebagai sebuah bentuk usaha pelestarian di Indonesia. Pada dasarnya kegiatan pelestarian di Indonesia tidak dapat dipisahkan dari munculnya kegiatan pelestarian pertama kalinya di dunia, di mana awal mulanya adalah saat terjadinya revolusi industry dan kemudian adanya Perang Dunia I, dimana banyak bangunan-bangunan bersejarah rusak dan hancur karenanya. Gambar 5 memperlihatkan sekilas gambaran tentang bagaimana perkembangan dan sejarah munculnya kegiatan pelestarian di dunia.
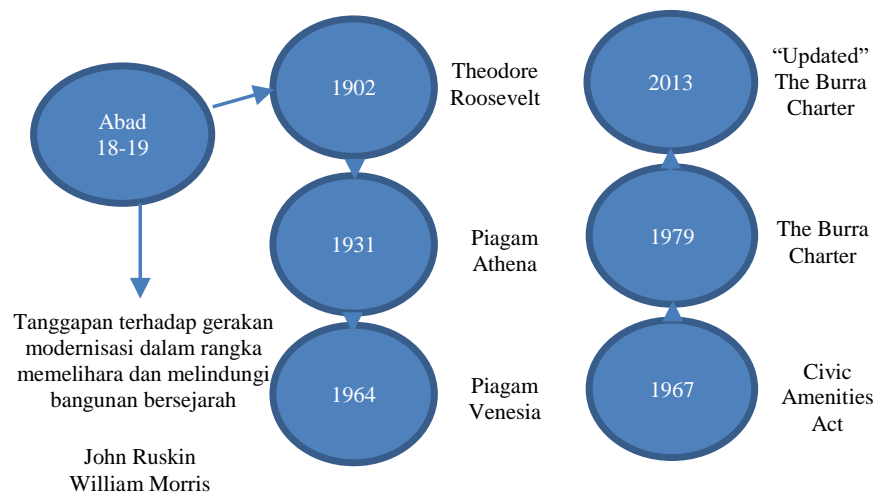

Gambar 6. Garis waktu dari sejarah dan perkembangan kegiatan pelestarian di dunia (Sumber: Analisis Peneliti, 2020)

Berdasarkan perkembangan tersebut, kegiatan pelestarian di Indonesia mengacu pada The Burra Charter yang diatur oleh UNESCO. Pada perkembangannya, kepedulian dan kebutuhan akan kegiatan pelestarian di Indonesia juga berkembang. Penetapan Kawasan bersejarah yang tadinya hanya mengacu pada peraturan UNESCO dengan tingkat internasional, saat ini di Indonesia, penetapan Kawasan bersejarah dapat dilakukan dalam tingkat nasional maupun local dengan mengadu pada UU RI No. 11 Tahun 2010 (Undang-Undang RI, 2010).

Konservasi itu sendiri dapat dimaknai sebagai sebuah penghembusan nafas ke dalam sebuah bangunan tua atau Kawasan tua, terutama yang memiliki karakter sejarah dan arti bagi sebuah kota. Kata konservasi itu sendiri merupakan kata yang berasal dari "conservation" yaitu "con" (together) dan "servare" (keep/ save) yang memiliki pengertian mengenai upaya memelihara apa yang kita punya (keep/save what you have), namun secara bijaksana (wise use) (Purwantiasning, 2013).

Pada dasarnya, konservasi memiliki tujuan untuk mengelola sebuah "tempat" atau "Kawasan bersejarah" dengan menerapkan sebuah perlakuan khusus, dimana nilai-nilai di dalamnya dapat dilestarikan dan diperhatikan sesuai kaidah-kaidah konservasi (Budihardjo, 1997). Dalam hal ini Budihardjo (1997) juga menjelaskan bahwa "tempat" di sini dapat dimaknai sebagai lahan, Kawasan, bangunan, kelompok bangunan dan lingkungan di sekitarnya. Pernyataan ini menggarisbawahi bahwa konservasi biasanya ditetapkan dalam suatu Kawasan yang memiliki karakter unik dan khusus dan menjadi identitas sebuah kota atau bahkan negara.

Dari paparan di atas, Saya mencoba untuk menyederhanakannya, bahwa Penetapan Kawasan Bersejarah dapat dibagi menjadi tiga tingkatan yaitu:

1. Penetapan tingkat internasional yang diatur oleh UNESCO

2. Penetapan tingkat nasional yang diatur oleh UU RI No. 11 Tahun 2020

3. Penetapan tingkat lokal yang ditetapkan oleh Pemerintah Daerah mengacu pada UU RI No. 11 Tahun 2020 baik di tingkat Kecamatan atau Kabupaten.

Pada poin nomor 2, penetapan tingkat nasional juga dibedakan menjadi dua penetapan, yaitu penetapan yang dilakukan oleh Pemerintah RI di bawah KEMENDIKBUD dan Pemerintah RI di bawah Direktorat Jendral PUPR yang berkolaborasi dengan Direktorat Jendral Cipta Karya dan Badan Pelestarian Pusaka Indonesia dengan dikeluarkannya Program Penataan dan Pelestarian Kota Pusaka.

\section{Penetapan Tingkat Internasional}

Seperti telah disampaikan sebelumnya, bahwa kegiatan pelestarian di Indonesia mengacu pada kaidah-kaidah pelestarian dari UNESCO. Dalam hal ini mengacu pada hasil konvensi tentang "the Protection of the World Cultural and Natural Heritage UNESCO" Tahun 1972. Hasil konvensi ini kemudian diratifikasi Pemerintah Indonesia pada 6 Juli 1989. 
Dari hasil konvensi tersebut, pada tahun 1991, Indonesia berhasil memperoleh status World Heritage terhadap dua buah Cagar Budaya yang unik yaitu Kompleks Candi Borobudur dan Kompleks Candi Prambanan. Hal ini tentunya membawa nama Indonesia di tingkat internasional. Kedua Cagar Budaya yang memiliki status Pusaka Dunia tersebut telah menjadi identitas Indonesia. Seluruh dunia mengenal Indonesia dari keberadaan dua PUsaka Dunia tersebut karena hasil penetapan World Heritage dari UNESCO. Setelah kedua buah Candi tersebut, menyusul tiga buah Cagar Alam di Indonesia yang ditetapkan oleh UNESCO sebagai Pusaka Dunia yaitu Taman Nasional Komodo, Taman Nasional Ujung Kulon dan Taman Nasional Lorentz di tahun yang sama yaitu 1991.

Penetapan tersebut selain membawa nama Indonesia, juga memberikan nilai peduli yang makin besar dari Indonesia terhadap seluruh Cagar Budaya dan Cagar Alamnya. Kelima Pusaka Dunia tersebut bukan hanya menjadi milik Indonesia saja namun juga menjadi milik dunia, sehingga tanggungjawab dalam pelestariannya juga tidak hanya dipangku oleh Indonesia, tapi juga oleh dunia.

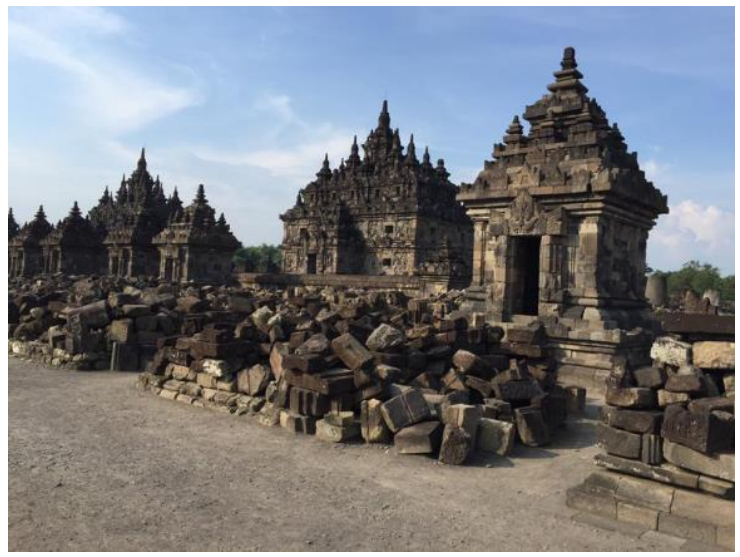

Gambar 7. Candi Plaosan merupakan bagian dari Kompleks Candi Prambanan yang merupakan Pusaka Dunia sejak 1991 (Sumber: Dokumentasi Peneliti, 2016)

Saat ini beberapa Pusaka Dunia Indonesia sedang mengalami penurunan kualitas yang menyebabkan adanya peringatan dari UNESCO. Beberapa pemberitaan di bulan Agustus 2021 ini memperlihatkan kondisi yang memprihatinkan terhadap beberapa Pusaka Dunia di Indonesia. Seperti yang telah disampaikan sebelumnya, bahwa Kota Liverpool mendapatkan peringatan dari UNESCO yang akhirnya berujung pada malapetaka pencabutan status World Heritage pada Kota Liverpool. Pemberitaan di Indonesia dengan Berita Utama "Setelah Kartu Merah Liverpool" memperlihatkan sebuah ancaman yang halus terhadap Indonesia. Kartu Merah di sini tidak ada kaitannya dengan persepakbolaan di Indonesia, namun berkaitan dengan status Pusaka Dunia pada beberapa Cagar Budaya dan Cagar Alam di Indonesia.

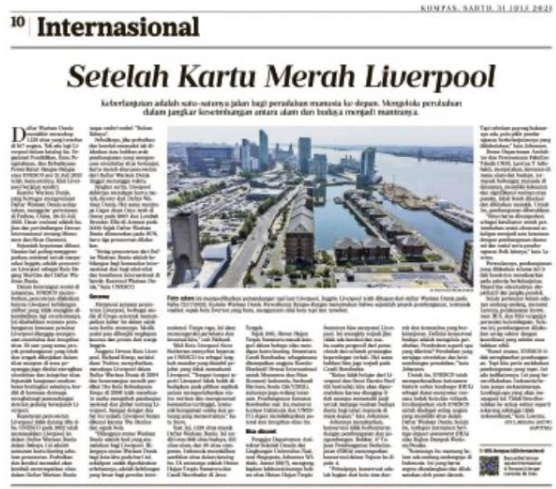

Gambar 8. Pemberitaan mengenai terancamnya Pusaka Dunia di Indonesia

(Sumber: Kompas Online, diakses 28 Agustus 2021)

\section{Jaga Status Borobudur}

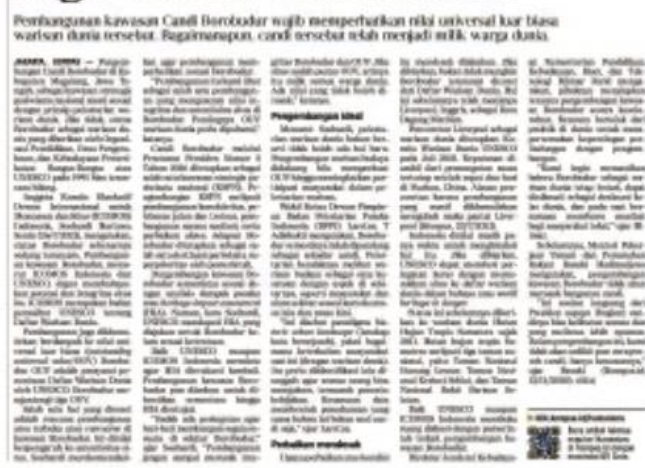

Gambar 9. Pemberitaan mengenai terancamnya Status Candi Borobudur sebagai Pusaka Dunia disampaikan oleh UNESCO

(Sumber: Kompas Online, diakses 28 Agustus 2021) 


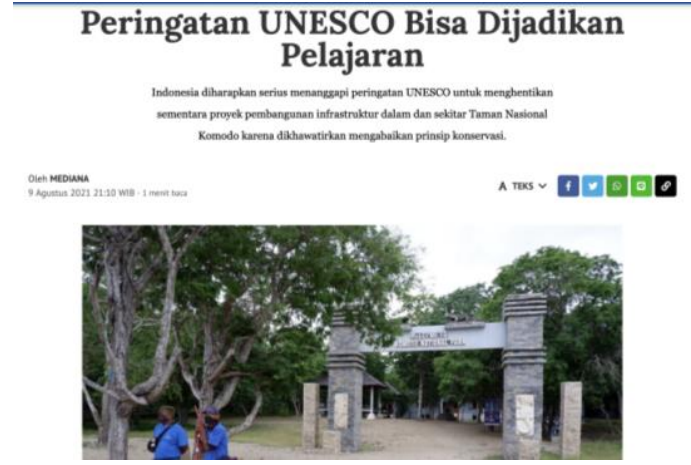

Gambar 10. Pemberitaan mengenai terancamnya Status Taman Nasional Komodo sebagai Pusaka Dunia disampaikan oleh UNESCO

(Sumber: Kompas Online, diakses 28 Agustus 2021)

\section{Penetapan Tingkat Nasional}

Pada penetapan tingkat nasional, kegiatan penetapan ini mengacu pada peratuan dan kaidah yang termaktub di dalam UndangUndang RI Nomor 5 Tahun 1992, yang disempurnakan kemudian di dalam UndangUndang RI Nomor 11 Tahun 2010 tentang Cagar Budaya di Indonesia. Di dalam UU RI Nomor 11 Tahun 2010 dijelaskan tentang Cagar Budaya yang dapat dimaknai sebagai berikut (Undang-Undang RI, 2010):

"bahwa cagar budaya berupa benda, bangunan, struktur, situs dan kawasan perlu dikelola oleh pemerintah dan pemerintah daerah dengan meningkatkan peran serta masyarakat untuk melindungi, mengembangkan dan memanfaatkan cagar budaya"

Sementara itu di dalam Undang-undang yang sama, juga dijelaskan tentang pengertian "penetapan", yaitu (Undang-Undang RI, 2010):

"Penetapan adalah pemberian status Cagar Budaya terhadap benda, bangunan, struktur, lokasi, atau satuan ruang geografis yang dilakukan oleh pemerintah kabupaten/kota berdasarkan rekomendasi Tim Ahli Cagar Budaya"

Dalam menetapkan sebuah obyek menjadi Cagar Budaya dalam hal ini dapat berupa bangunan maupun Kawasan bersejarah, perlu ada kaidah-kaidah dan aturannya. Setidaknya ada beberapa kriteria yang harus dipenuhi bagi sebuah obyek sampai dapat ditetapkan sebagai Cagar Budaya. Berdasarkan (UndangUndang RI, 2010), benda, bangunan, atau struktur dapat diusulkan sebagai Benda Cagar
Budaya, Bangunan Cagar Budaya, atau Struktur Cagar Budaya apabila memenuhi kriteria:

a. berusia 50 (lima puluh) tahun atau lebih;

b. mewakili masa gaya paling singkat berusia 50 (lima puluh) tahun;

c. memiliki arti khusus bagi sejarah, ilmu pengetahuan, pendidikan, agama, dan/atau kebudayaan;

d. memiliki nilai budaya bagi penguatan kepribadian bangsa.

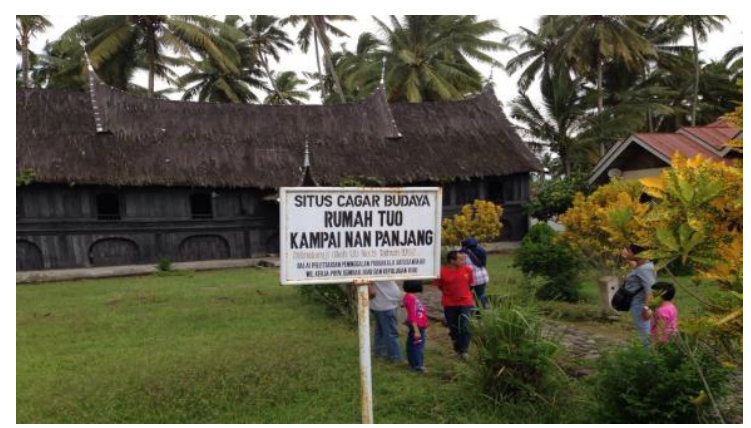

Gambar 11. Rumah Tuo Kampai Nan Panjang merupakan Rumah Gadang tertua di Minangkabau,

Sumatera Barat yang ditetapkan sebagai Cagar Budaya Tingkat Nasional

(Sumber: Dokumentasi Peneliti, 2015)

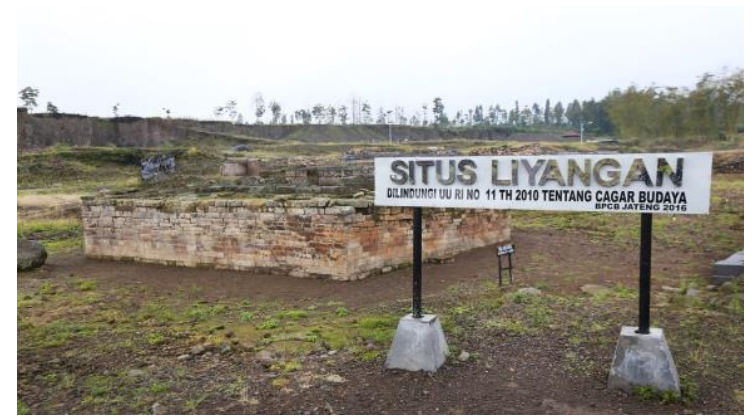

Gambar 12. Situs Liyangan di Parakan, Temanggung, Jawa Tengah ditetapkan sebagai Cagar Budaya Tingkat Nasional

(Sumber: Dokumentasi Peneliti, 2019)

Penetapan tingkat nasional juga dilakukan tidak hanya oleh KEMENTERIAN PENDIDIKAN DAN KEBUDAYAAN, namun juga oleh kolaborasi antara Direktorat Jendral Ciptakarya, PUPR dan Badan Pelestarian Pusaka Indonesia dengan program Kota Pusaka. Penetapan Kota Pusaka oleh ketiga dinas ini merupakan Program Penataan Pelestarian Kota Pusaka yang digulirkan sejak Tahun 2012. Kegiatan ini bertujuan untuk memberikan upaya nyata dalam melestarikan aset-aset pusaka bangsa yang tersebar di berbagai kota di Indonesia. 
Kota Pusaka dalam hal ini dimaknai sebagai Kota yang di dalamnya terdapat kawasan cagar budaya dan atau bangunan cagar budaya yang memiliki nilai-nilai penting bagi kota, menempatkan penerapan kegiatan penataan dan pelestarian pusaka sebagai strategi utama pengembangan kotanya (Dirjen Ciptakarya Online, 2012).

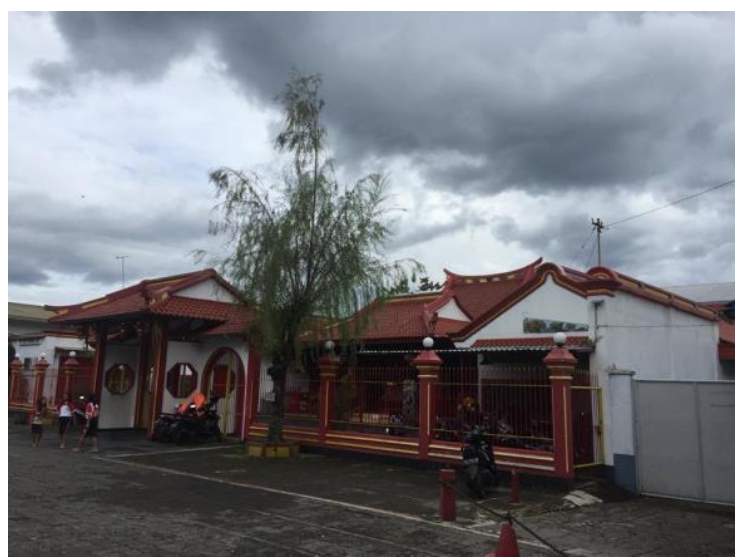

Gambar 13. Klenteng Hok Tek Tong salah satu bangunan berkarakter di Parakan yang menjadi salah satu alasan Kota Parakan ditetapkan menjadi Kota Pusaka oleh P3KP di tahun 2015 (Sumber: Dokumentasi Peneliti, 2019)

\section{Penetapan Tingkat Lokal}

Penetapan tingkat lokal dilakukan oleh Pemerintah Daerah dalam hal ini Camat, Bupati Walikorta, atau Gubernur yang tetap mengacu pada Undang-Undang RI Nomor 11 Tahun 2010. Dengan Surat Ketetapan yang dikeluarkan oleh Pemerintah Daerah tersebut, dimaksudkan agar masyarakat lebih peduli dengan keberadaan bangunan-bangunan tua bersejarah yang memiliki nilai sejarah, estetika, budaya dan spiritual. Kegiatan penetapan tingkat lokal ini juga dilakukan sebagai salah satu bentuk apresiasi Pemerintah Daerah kepada masyarakat yang peduli akan kegiatan pelestarian. Gsmbar 14 dan 15 memperlihatkan salah satu bangunan rumah yang ditetapkan sebagai salah satu Bangunan Warisan Budaya di Yogyakarta di bawah ketetapan Walikota Yogyakarta Nomor 435 tahun 2018. Rumah ini merupakan hunian salah satu mantan abdi dalem Keraton Yogyakarta Hadiningrat yang saat ini difungsikan sebagai Taman Bermain dan Taman Kanak-Kanak AL-Husna. Lokasi Bangunan Warisan Budaya ini terletak di Jalan Gajah Mada NOmor 1, Yogyakarta.

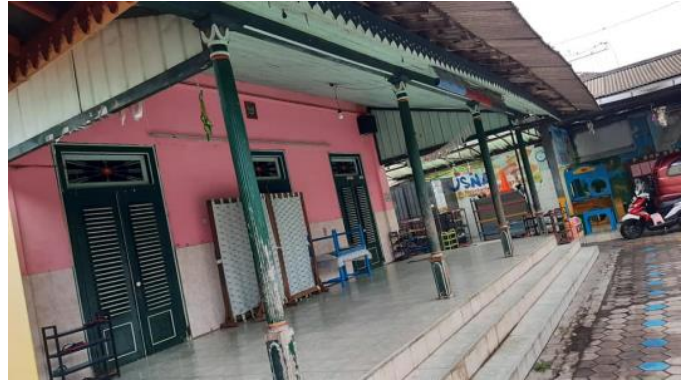

Gambar 14. Bangunan Warisan Budaya (Sumber : Dokumentasi Pribadi, 2020)

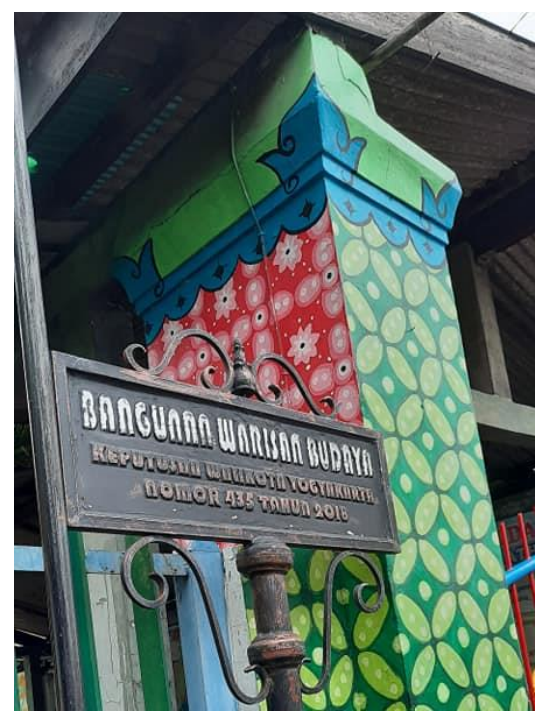

Gambar 15. Penetapan Tingkat Lokal oleh Walikota Yogyakarta

(Sumber : Dokumentasi Pribadi, 2020)

\section{KESIMPULAN}

Paparan di dalam tulisan ini setidaknya telah memberikan gambaran bagaimana pentingnya penetapan sebuah Cagar Budaya baik di tingkat Internasional, Nasional maupun Lokal. Ketiga tingkat tersebut memiliki peran dan tanggungjawab yang berbeda-beda tentunya. Dapat disimpulkan di sini bahwa penetapan sebuah Kawasan bersejarah sebagai Kawasan konservasi dapat meningkatkan kepedulian dan kemauan melestarikan serta keinginan untuk memahami dari masyarakat tentang pentingnya peninggalan-peninggalan bersejarah sebagai cagar budaya

\section{REFERENSI}

BBC News. (2021). Unesco Report Says Liverpool Should Lose World Heritage Status. Retrieved August 28, 2021, from https://www.bbc.com/news/uk-england- 
merseyside- 57556884

Bianet Online. (2021). UNESCO May Strip Hagia Sophia And Chora Of World Heritage Site Status. Retrieved August 18, 2021, from https://bianet.org/english/politics/247644unesco-may-strip-hagia-sophia-andchora-of-world-heritage-site-status

BPPI Online. (2021). Dialog Dengan Menteri Sekretaris Negara RI. Retrieved August 28, 2021, from https://bppiindonesianheritagetrust.org/be rita_view.php?berita=Dialog+dengan+Me nteri+Sekretaris+Negara+RI

Brolin, B. (1976). The Failure of Modern Architecture. Studio Vista.

Budihardjo, E. (1997). Preservation and Conservation of Cultural Heritage in Indonesia. Yogyakarta, Indonesia.: Universitas Gadjah Mada Press.

Dirjen Ciptakarya Online. (2012). Program Penataan dan Pelestarian Kota Pusaka. Retrieved August 28, 2021, from http://sim.ciptakarya.pu.go.id/kotapusaka/ page/3-program-penataan-danpelestarian-kota-pusaka-p3kp

Hopkirk, E. (2021). Unesco Strips World Heritage Status From Liverpool. (Dalam Building Design Online). Retrieved August 28, 2021, from https://www.dw.com/en/unesco-stripsliverpool-of-world-heritage-status/a58578428

Purwantiasning, A. (2013). Designation of Conservation Area as an Effort to Preserve a Local. Proceeding International Seminar on Genius Loci \#01. UIN Makassar.

Undang-Undang RI. Undang Undang RI No 11 2010 Tentang Cagar Budaya. , Pub. L. No. 11 (2010).

Worskett, R. (1969). The Character of Towns: An Approach to Conservation. London: The Architectural Press. 